\title{
The Protective Effects of Sika Deer Antler Protein on Cisplatin-Induced Nephrotoxicity
}

\author{
Huihai Yang ${ }^{a}$ Wei Li ${ }^{a}$ Lulu Wang ${ }^{b}$ Wenqing Li ${ }^{a}$ Hang Sun ${ }^{a}$ Xiaofeng He \\ Jing Zhanga
}

aDepartment of Traditional Chinese Pharmacology, College of Traditional Chinese Medicine, Jilin Agricultural University, Changchun, ${ }^{b}$ Department of Traditional Chinese Pharmacology, College of Medicine, Changchun Science- Technology University, Changchun, China

\section{Key Word}

Oxidative stress $\bullet$ Apoptosis $・$ Inflammation $・$ Renal protection

\begin{abstract}
Background/Aims: This study measured the effect of Sika deer (Cervus nippon Temminck) antler protein (SDAPR), glycoproteins (SDAG), and polysaccharides (SDAPO) on cisplatininduced cytotoxicity in HEK 293 cells, and investigated the effect of SDAPR against cisplatininduced nephrotoxicity in mice. Methods: Cell viability was measured by MTT assay. ICR mice were randomly divided into five groups: control, cisplatin with vehicle, and cisplatin with SDAPR at three concentrations: 5, 10, or $20 \mathrm{mg} / \mathrm{kg}$, p.o., $10 \mathrm{~d}$. Cisplatin was injected on $7^{\text {th }}$ day (25 mg/kg, i.p.). Renal function, oxidative stress, levels of inflammatory factors, and expression of apoptosis-related proteins were measured in vivo. Renal tissues were stained with TUNEL and H\&E to observe renal cell apoptosis and pathological changes. Results: Pretreatment with SDAPR $(125-2000 \mu \mathrm{g} / \mathrm{mL})$ significantly improved cell viability, with an $\mathrm{EC}_{50}$ of approximately 1000 $\mu \mathrm{g} / \mathrm{mL}$. SDAPR also ameliorated cisplatin-induced histopatholo- gic changes, and decreased blood urea nitrogen (BUN) and creatinine $(\mathrm{Cr})(P<0.05)$. Western blotting analysis showed SDAPR clearly decreased expression levels of cleaved-caspase-3 and Bax, and increased the expression level of $\mathrm{BCl}-2(P<0.01)$. Additionally, SDAPR markedly regulated oxidative stress markers and inflammatory cytokines $(P<0.05)$. TUNEL staining showed decreased apoptosis after SDAPR treatment $(P<0.01)$. Conclusions: These results indicate that SDAPR can be an effective dietary supplement, to relieve cisplatin-induced nephrotoxicity by improved antioxidase activity, suppressed inflammation, and inhibited apoptosis in vivo.
\end{abstract}




\section{Cellular Physiology Cell Physiol Biochem 2017;43:395-404

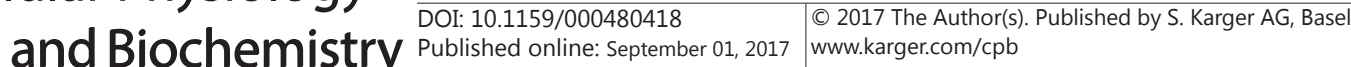

Yang et al.: SDAPR Protect CDDP-Induced Nephrotoxicity

\section{Introduction}

The World Cancer Report of 2014 identified a high incidence of cancer in China. Clinical trials have shown that the most common cancers include esophagus, lung, and stomach [1]. Currently, there are three types of therapies for cancers, surgery, radiation, and drug therapy. In medicinal treatment, platinum-based drugs are commonly used for cancer treatment. Platinum-based drugs accounted for $70-80 \%$ of antitumor chemotherapy in China [2], including cisplatin (CDDP), carboplatin (CBP), oxaliplatin (L-OHP), nedaplatin (NDP), and lobaplatin (LBP). Of these, CDDP is most common in clinical application [3] .

Cisplatin (cis-diamminedichloroplatinum, CDDP) is an anticancer agent used in treating various solid tumors in the head, neck, lung, esophagus, bladder, and other parts of the body. [4]. However, there are many side effects of CDDP, including peripheral neurotoxicity, ototoxicity, myelosuppression, and nephrotoxicity [5]. Of these effects, the clinical limitation of CDDP is nephrotoxicity [6]. The clinical symptoms of CDDP nephrotoxicity are renal damage and dysfunction, and approximately $25-35 \%$ of patients showed signs of nephrotoxicity following a single dose of CDDP [7]. There are few effective remedies to repair renal structure and improving renal function [8]. Studies have indicated that the molecular mechanism of CDDP nephrotoxicity is related to oxidative stress [9], inflammation [10], and apoptosis [11]. Therefore, it is necessary to identify strategies to alleviate CDDP nephrotoxicity.

Velvet antlers are one of the most important animal medicines, and have been used for a variety of functions for more than two thousand years, including tissue repair, treatment of bone-resorption diseases, and treatment of rheumatoid arthritis [12]. Velvet antlers from Sika deer or red deer are deemed as medicinal antlers in national pharmacopoeias in China, Japan, and Korea [12]. In-depth studies have demonstrated the presence of mineral elements, polypeptides, proteins, amino acids, polysaccharides, and fatty acids in velvet antlers [13]. More recently, it has been reported that the aqueous extract of Sika deer antlers can protect against CDDP-induced nephrotoxicity in HEK 293 cells and mice [14]. In the present study, we explored which active ingredient of Sika deer antler aqueous extract can protect against CDDP nephrotoxicity and investigate the potential mechanisms of action.

\section{Materials and Methods}

\section{Sample extraction}

Samples of Sika deer antler powder (150 g) were purchased from Shuangyang deer farm (Changchun, China) and authenticated by Ph.D Zhang. The powder was put into $300 \mathrm{~mL}$ of water, and was extracted by ultrasound device (KQ5200DB, Kunshan, China) at $60^{\circ} \mathrm{C}$ for $0.5 \mathrm{~h}$. The solution was filtered and collected, three times. The material was precipitated by addition of $95 \%(\mathrm{v} / \mathrm{v}$ ) ethanol to a final concentration of $85 \%$ $(\mathrm{v} / \mathrm{v})$ and then maintained for $12 \mathrm{~h}$ at $4^{\circ} \mathrm{C}$. Next, the precipitate was collected by centrifugation $(8000 \mathrm{rpm}$, $10 \mathrm{~min}$ ). The filtrate was collected and the alcohol was removed using a rotary evaporator (R206, Shanghai, China). Then, the extracted solution was lyophilized in a freeze dryer (Telstar, Spain) to obtain the Sika deer antler protein powder (SDAPR). The precipitate was divided into two equal parts, and one part was lyophilized to obtain Sika deer antler glycoprotein (SDAG). Another part was treated to remove the proteins using the Sevage method and then lyophilized to obtain Sika deer antler polysaccharide (SDAPO).

\section{Cell culture}

Immortalized human embryonic kidney 293 cells (HEK 293) and human prostate cancer cells (PC$3 \mathrm{M})$ were purchased from ATCC and stored at the Laboratory of Molecular Biology in Jilin Agricultural University, for use in the in vitro studies. The HEK 293 cells were cultured in DMEM (Hyclone, USA) and PC$3 \mathrm{M}$ cells were cultured in RPMI1640 (Hyclone, USA), both supplemented with $10 \%$ fetal bovine serum (FBS, Hyclone, USA) and 1\% penicillin/streptomycin (Hyclone, USA). The cells were maintained in a humidified incubator with $5 \% \mathrm{CO}_{2}$ at $37^{\circ} \mathrm{C}$. 


\section{Cellular Physiology Cell Physiol Biochem 2017;43:395-404 \begin{tabular}{l|l|l} 
DOI: 10.1159/000480418 & $\begin{array}{l}\text { (C) 2017 The Author(s). Published by S. Karger AG, Basel } \\
\text { www.karger.com/cpb }\end{array}$
\end{tabular} \\ Published onlIne: September 01, 2017 www.karger.com/cpb}

MTT assay

The MTT assay, a quantitative colorimetric assay with 3-(4, 5-dimethylthiazol -2-yl)-2, 5diphenyltetrazolium bromide, was used for determining cell viability. Cells were seeded into 96-well plates and cultured at $37^{\circ} \mathrm{C}$ for $24 \mathrm{~h}$. After an appropriate incubation period, cells were pretreated with SDAPR, SDAPO, or SDAG for $24 \mathrm{~h}$, and then exposed to cisplatin (25 $\mu \mathrm{M}$, Civi Chemical Technology, China) or not for $24 \mathrm{~h}$. After treatment, $20 \mu \mathrm{L}$ MTT solution [15] (5 mg/mL, Biotopped, China) was added to the wells and incubated at $37^{\circ} \mathrm{C}$ for $4 \mathrm{~h}$. Then, $150 \mu \mathrm{L}$ DMSO (Shanghai Civi Chemical Technology, China) was added to each well, and the plates were agitated for $10 \mathrm{~min}$. Finally, the absorbance was measured at $490 \mathrm{~nm}$ using a microplate reader (Nano, Germany).

\section{Animals and experimental protocol}

Animal experiments were designed and approved by the Committee for the Purpose of Control and Supervision of Experiments on Animals. Animal experiments were executed by the Institutional Animal Ethic Committee of Department of Biochemistry, Jilin Agricultural University, Changchun, China.

ICR male mice $(n=40)$ weighing $20 \pm 2$ g were utilized in the studies, and were purchased from the Yisi Laboratory Animal Technology Co. Ltd. (SCXY-2011-0004). Mice were housed at controlled temperature (28 $\pm 2^{\circ} \mathrm{C}$ ) and humidity $(65 \pm 5 \%)$ with $12 \mathrm{~h}$ light-dark cycle in animal cages. The experiments were performed in accordance with the National Institutes of Health Guide for the Care and Use of Laboratory Animals. All mice were freely fed rodent chow and tap water. Mice were divided into five groups of 8 animals each. Group I served as the control, and received distilled water (vehicle of SDAPR; p.o.) for 10 consecutive days and normal saline (vehicle of CDDP; i.p.) on the seventh day. Group II received distilled water for 10 consecutive days and CDDP (25 mg/kg; i.p.) dissolved with saline as a single intraperitoneal injection on the seventh day. Group III, IV, and V received a low-dose ( $5 \mathrm{mg} / \mathrm{kg}$; p.o.), a middle-dose (10 mg/kg; p.o.), or a high-dose (20 $\mathrm{mg} / \mathrm{kg}$; p.o.), respectively of SDAPR solution for 10 consecutive days and CDDP (25 mg/kg; i.p.) dissolved with saline as a single intraperitoneal injection on the seventh day. On the tenth day, before mice were euthanized, blood samples were collected from ophthalmic veins. Renal tissues were collected immediately. One kidney was removed to determine histological analysis; the other was stored at $-80^{\circ} \mathrm{C}$ for biochemical analysis.

Measurement of body weight and renal weight in mice

In the experimental period, the mice were weighed every day, and the rate of weight change was calculated. After the mice were sacrificed, the kidneys were quickly excised, cleaned, and weighed. Then, the kidney index was calculated as a ratio value of the renal weight over the body weight.

Determination of kidney function test

Blood urea nitrogen (BUN) and creatinine (Cr) levels were measured to assess renal function in mice. After the experimental period, blood samples were collected and centrifuged (3500 rpm, $15 \mathrm{~min}$ ) to separate the serum. The levels of BUN and Cr were determined according to the commercial kit instructions (Nanjing Jiancheng Biotech. Co. Ltd.; Nanjing, China).

Measurement of oxidative stress markers

After the experimental period, oxidative stress markers were examined in mice, including super oxide dismutase (SOD), catalase (CAT), glutathione (GSH), and malondialdehyde (MDA). The activities of SOD, CAT, GSH, and the level of MDA were determined in renal tissues according to the commercial kit instructions (Nanjing Jiancheng Biotech. Co. Ltd.; Nanjing, China).

\section{ELISA assay}

After the experimental period, inflammation markers tumor necrosis factor- $\alpha$ (TNF- $\alpha$ ) and interleukin-6 (IL-6) were examined in serum and renal tissues. The cytokine levels of TNF- $\alpha$ and IL-6 were detected in serum and renal tissues by mouse ELISA kits according to the manufacturer's instructions. All ELISA kits were purchased from Shanghai Lengton Bioscience Co., Ltd. (Shanghai, China). 
Measurement of apoptosis markers

Western blot analysis was used to measure the total protein levels of cleaved-caspase-3, Bax, and $\mathrm{Bcl}-2$ in renal tissues. Total proteins were extracted using RIPA (Beyotime, China). The BCA protein assay kit was used to quantify protein concentrations. Then, the protein samples were separated by $12 \%$ sodium dodecyl sulfate-polyacrylamide gel electrophoresis (SDS-PAGE) and transferred to PVDF membranes. The membranes were blocked with $5 \%$ skim milk powder overnight. Then, the membranes were incubated with the primary rabbit antibodies of caspase-3 (1:1000, Abcam, UK), Bax (1:500, Boster, China), Bcl-2 (1:500, Boster, China), and $\beta$-actin (1:500, Bioss, China) at $4^{\circ} \mathrm{C}$ overnight. Next, the membranes were washed and incubated with horseradish peroxidase conjugated secondary antibodies at room temperature for $2 \mathrm{~h}$. Finally, the bands were visualized by ECL kit (Solarbio, Beijing, China) and analyzed by Image pro plus.

\section{TUNEL assay}

The terminal deoxynucleotidyl transferase mediated dUTP nick-end labeling (TUNEL) assay was used to measure the level of apoptosis in mice using the TUNEL Apoptosis Detection Kit (Nanjing Jiancheng Biotech, China) The numbers of apoptotic cell as defined by chromatin condensation or nuclear fragmentation were counted.

\section{Histopathological evaluation}

After the mice were euthanized, the right kidneys were collected and immediately embedded in OTC. Then, the sections were cut to $6 \mu \mathrm{m}$ pieces and stained with the H\&E assay. Finally, renal histopathological sections were observed by light microscopy (Leica, Germany).

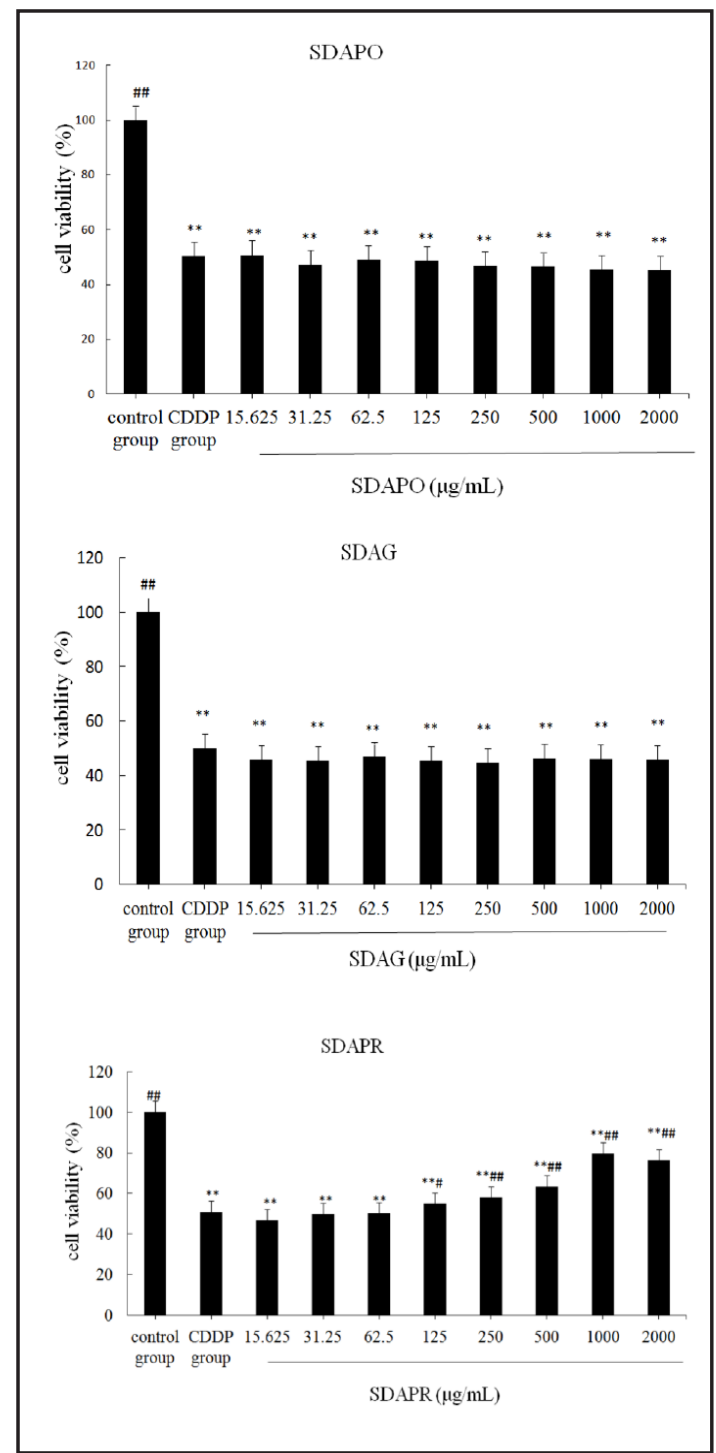

Fig. 1. The effects of SDAPO, SDAG or SDAPR treatment on CDDP-induced damage in HEK293 cells.

\section{Statistical analysis}

The results were expressed as the mean \pm SD. One-way analysis of variance (ANOVA) was used to compare different groups. $\mathrm{P}<0.05$ and $\mathrm{P}<0.01$ were used to define the statistical significance.

\section{Results}

Effects of SDAPR, SDAPO, or SDAG treatment on CDDP-induced damage in HEK 293 cells

HEK 293 cells were treated with SDAPR, SDAPO, or SDAG before receiving CDDP. To determine the effects of these treatments on cell viability, the MTT method was used. As shown in Fig. 1, CDDP significantly reduced cell viability compared to the control group cells $(P<0.01)$, with a $\mathrm{LD}_{50}$ of approximately $25 \mu \mathrm{M}$. Treatment with nine concentrations of SDAPR $(0-2000 \mu \mathrm{g} / \mathrm{mL})$ for $24 \mathrm{~h}$ provided protection against CDDP-induced cell damage in a dose-dependent manner $(P<0.05)$, with an $\mathrm{EC}_{50}$ of approximately $1000 \mu \mathrm{g} / \mathrm{mL}$. However, the protection effect of SDAPO or SDAG was not significant.

\section{KARGER}


Effect of SDAPR on PC-3M cell viability

In order to evaluate the toxicity of SDAPR on PC-3M cells, the cell viability was determined by MTT assay. As shown in Fig. $2 \mathrm{~A}$, the results indicate that cytotoxic levels of SDAPR affect PC-3M cells viability in a dose-dependent manner $(P<0.05)$. The $\mathrm{LD}_{50}$ value of SDAPR is approximately $400 \mu \mathrm{g} /$ mL. As shown in Fig. 2B, SDAPR (100-900 $\mu \mathrm{g} / \mathrm{mL})$ combined with CDDP $(10 \mu \mathrm{M})$ with synergistic anti-tumor effect. These data demonstrated that the SDAPR treatment does not protect against tumor cells, and does not affect the therapeutic effect of CDDP.

Effect of SDAPR treatment on CDDPinduced kidney dysfunction in mice

Body weight and the kidney index were measured. As shown in Table 1, CDDP produced a significant weight reduction and kidney index increase compared with the control group. Compared with the mice that received CDDP alone, the mice that also received SDAPR showed significantly higher weights although still lower than the control group mice. Additionally, SDAPR pretreatment significantly decreased the kidney index $(P<0.05)$.

The levels of $\mathrm{Cr}$ and BUN were measured. As shown in Fig. 3, the levels of $\mathrm{Cr}$ and BUN were significantly increased after CDDP treatment, compared with the control group $(P<0.01)$. SDAPR pretreatment significantly decreased the levels of $\mathrm{Cr}$ and BUN compared to the levels in the group with only CDDP in a dose-dependent manner $(P<0.05)$.

Effect of SDAPR treatment on CDDPinduced oxidative stress

As shown in Fig. 4, the activities of antioxidant enzymes (SOD, CAT, and GSH) were significantly decreased, and the level of lipid peroxidation products (MDA) was significantly increased after CDDP administration in vivo $(P<0.01)$. Prior treatment with SDAPR markedly suppressed the MDA level and increased the activity of antioxidant enzymes compared to the CDDP only group $(P<0.05)$. These data indicate that SDAPR treatment provides partial protection to the CDDP-induced oxidative stress damage in mice kidneys.

\section{Effect of SDAPR treatment on CDDP-induced inflammation}

TNF- $\alpha$ and IL- 6 levels are two key markers of inflammation. We evaluated the effect of SDAPR on CDDP-induced inflammation in serum and renal tissues by measuring the levels of TNF- $\alpha$ and IL- 6 by ELISA. As shown in Fig. 5, the results showed that the secretions of TNF- $\alpha$
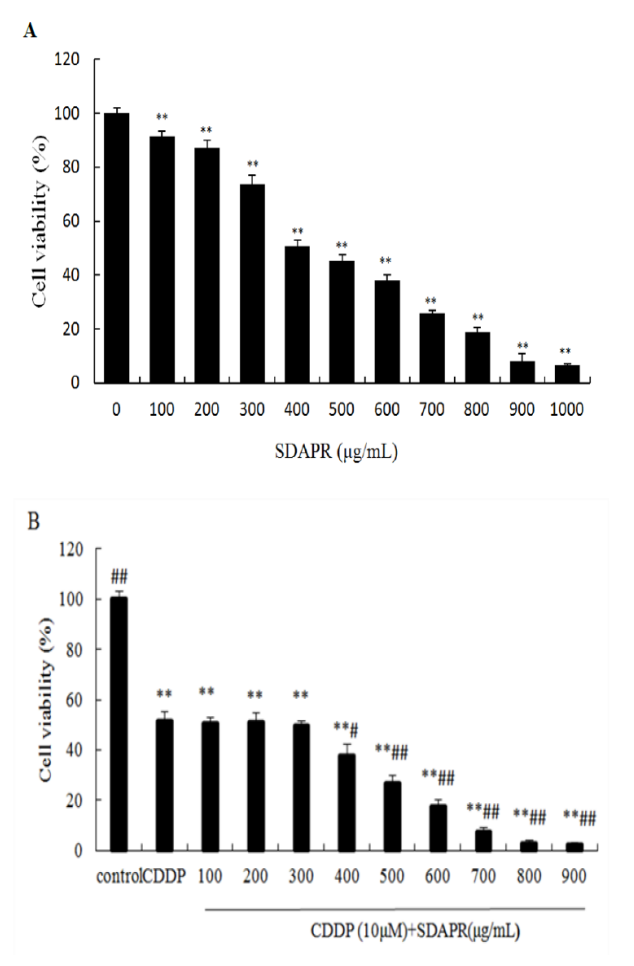

Fig. 2. The effects of SDAPR treatment on cytotoxicity in PC-3M cells. (A) The PC-3M cells treated with SDAPR(0- $1000 \mu \mathrm{g} / \mathrm{mL}$ ) for $24 \mathrm{~h}$. (B) (A) The PC-3M cells treated with cisplatin $(10 \mu \mathrm{M})$ and SDAPR(100$1000 \mu \mathrm{g} / \mathrm{mL}$ ) for $24 \mathrm{~h}$.

Table 1. Effect of SDAPR treatment on CDDP-induced alterations in body weight and kidney index. Values are expressed as means \pm SD $(n=6-8) .{ }^{*} p<0.05$ vs. Control group. ${ }^{* *} p<0.05$ vs. Control group. ${ }^{\#} p<0.05$ vs. CDDP group. ${ }^{\# \#} p<0.01$ vs. CDDP group.

\begin{tabular}{llllll} 
& $\begin{array}{l}\text { Initial } \\
\text { weight }\end{array}$ & $\begin{array}{l}\text { Final } \\
\text { weight }\end{array}$ & $\begin{array}{l}\text { Change of } \\
\text { weight }\end{array}$ & Mortality & $\begin{array}{l}\text { Kidney index } \\
(\%)\end{array}$ \\
\hline $\begin{array}{l}\text { control group } \\
\text { CDDP group }\end{array}$ & $27.22 \pm 1.46$ & $29.11 \pm 2.28$ & $2.68 \pm 1.18$ & $0 / 8$ & $0.82 \pm 0.10$ \\
$\begin{array}{l}\text { low-level group } \\
\text { (5mg/kg) }\end{array}$ & $28.78 \pm 1.89$ & $27.43 \pm 1.67$ & $-3.45 \pm 1.51^{* *}$ & $2 / 8$ & $1.19 \pm 0.06^{*}$ \\
$\begin{array}{l}\text { middle-level } \\
\text { group }\end{array}$ & $30.06 \pm 1.55$ & $27.06 \pm 0.86$ & $-3.24 \pm 1.68$ & $1 / 8$ & $0.886 \pm 0.90^{\sharp}$ \\
$\begin{array}{l}(10 \mathrm{mg} / \mathrm{kg}) \\
\text { high-level }\end{array}$ & $29.50 \pm 1.63$ & $28.16 \pm 0.71$ & & & $0.85 \pm 0.06^{\#}$ \\
$\begin{array}{l}\text { group } \\
(20 \mathrm{mg} / \mathrm{kg})\end{array}$ & & & $-1.06 \pm 1.63^{\# \#}$ & $0 / 8$ & \\
\hline
\end{tabular}



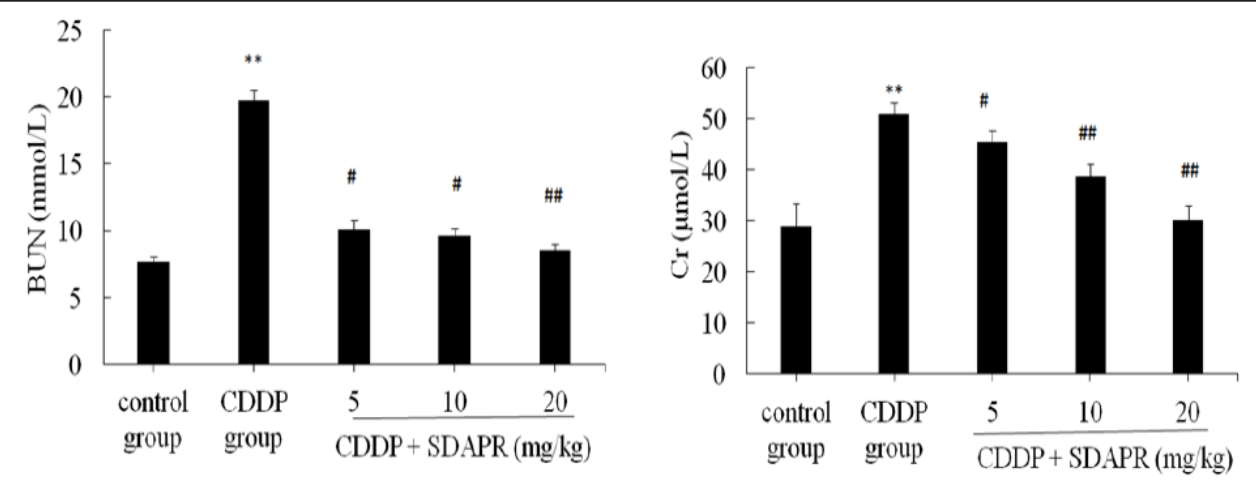

Fig. 3. Effect of SDAPR treatment on CDDP-induced alteration BUN and SCr levels in mice.

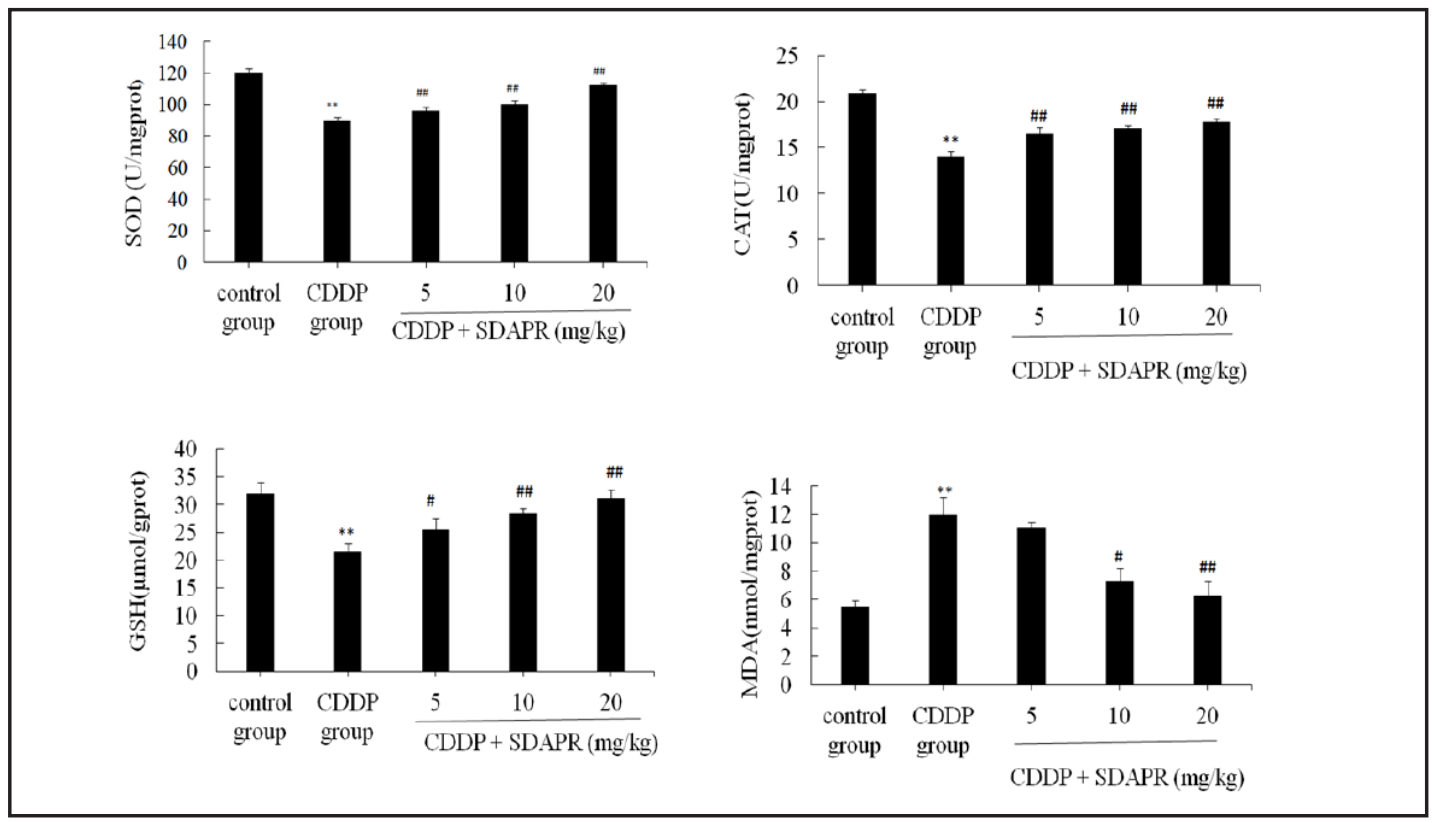

Fig. 4. Effect of SDAPR treatment on CDDP-induced the oxidative stress parameters in mice.

and IL-6 were dramatically increased after CDDP treatment $(P<0.01)$. However, SDAPR markedly reduced CDDP-induced inflammatory cytokine production $(P<0.05)$.

\section{Effect of SDAPR treatment on CDDP-induced apoptosis}

To evaluate the protective effect of SDAPR on CDDP-induced apoptosis, we analyzed the activities of caspase-3, Bax, and Bcl-2 in renal tissues. Apoptosis positive cells were identified by TUNEL staining. As the results in Fig. 6A show, SDAPR significantly decreased the CDDPinduced activity of Bax and increased activities of caspase-3 and Bcl-2 in a dose-dependent manner $(P<0.01)$. As shown in Fig. 6B, the renal apoptosis rate was significantly higher in the CDDP group compared to the control group $(P<0.01)$. Compared with the CDDP group, SDAPR significantly decreased the renal apoptosis rate $(P<0.01)$. These data suggest that SDAPR exerts inhibitory effects on CDDP-induced renal proximal tubule cell apoptosis.

Effect of SDAPR treatment on CDDP-induced kidney histopathological changes

As shown in Fig. 7, renal tissues showed a normal structure in the renal tubules (Fig. $7 \mathrm{~A}, \mathrm{a})$. However, we observed diffuse acute tubular necrosis, cellular vacuolization, and 
Fig. 5. Effects of SDAPR treated on CDDP-induced inflammatory parameters in serum and kidney tissues.

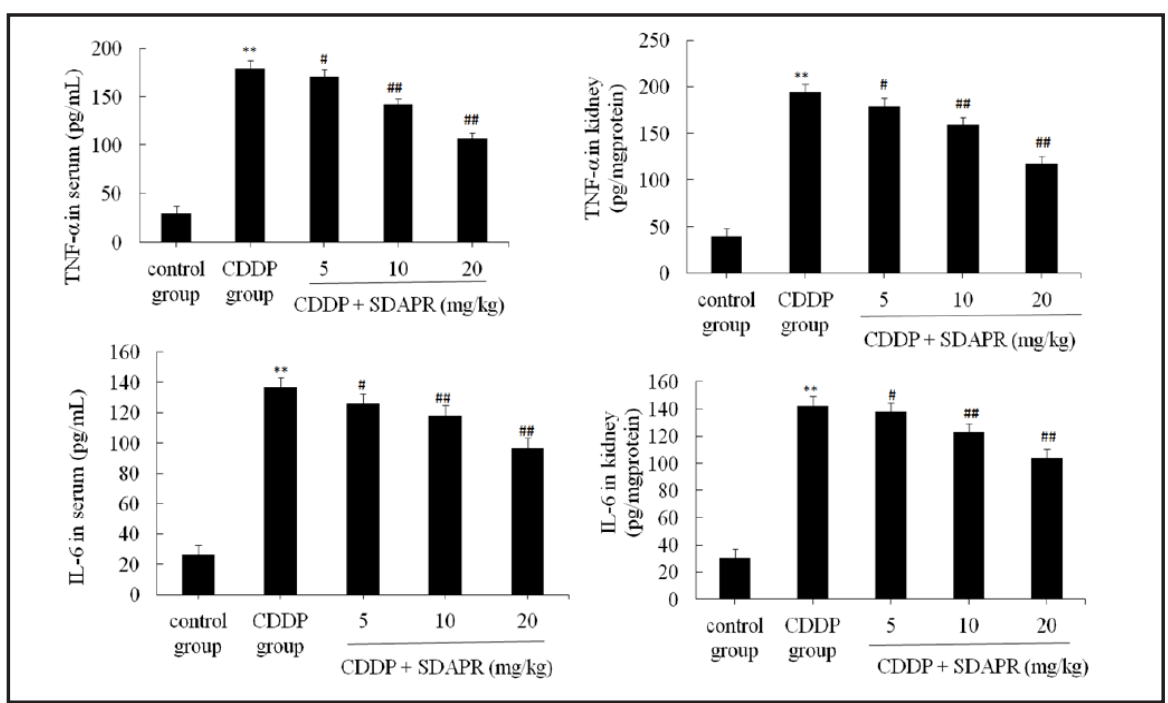

Fig. 6. Effect of SDAPR treated on CDDP-induced apoptosis in kidney injury. (A) Cleaved- caspase-3, Bax and Bcl-2 activities were determined by western blotting. (B) Effect of SDAPR on the apoptosis rate of kidney tissues.

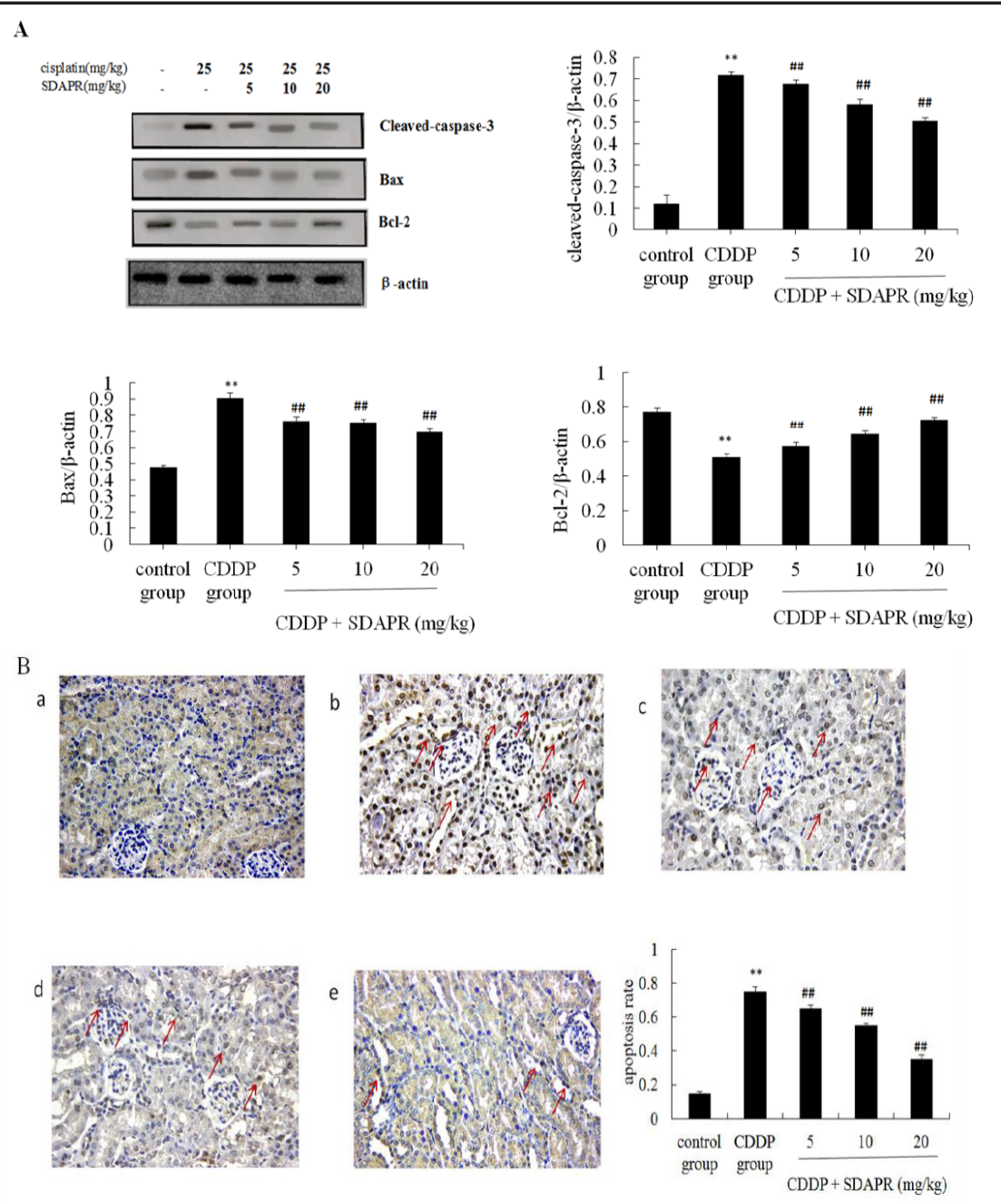

cast formation in the CDDP group (Fig. 7B, b). Compared to the CDDP only group, SDAPR significantly attenuated the CDDP-induced histopathological changes in a dose-dependent manner (Fig. 7C-E, c-e).

\section{KARGER}




\section{Cellular Physiology and Biochemistry}

Fig. 7. Histopathological changes of kidney tissues.

\section{Discussion}

CDDP-induced nephrotoxicity is a significant clinical problem. Hence, improved understanding of the pathophysiological processes behind CDDP-induced nephrotoxicity is critical for the development of new therapeutic strategies.

CDDP administration was previously found to affect renal function, and biochemical analysis showed that the levels of $\mathrm{Cr}$ and BUN renal function indicators were significantly increased after CDDP injection [16]. Our data show that SDAPR alleviated CDDP-induced renal function damage.

Previous studies demonstrated that CDDP alters kidney function and cause structural changes in kidneys. CDDP accumulates in renal tissues, damaging renal tubules and glomerulus [17]. The oxidative/nitrosative stress response, inflammation, and renal apoptosis are recognized as potential molecular mechanisms to explain the acute kidney injury caused by
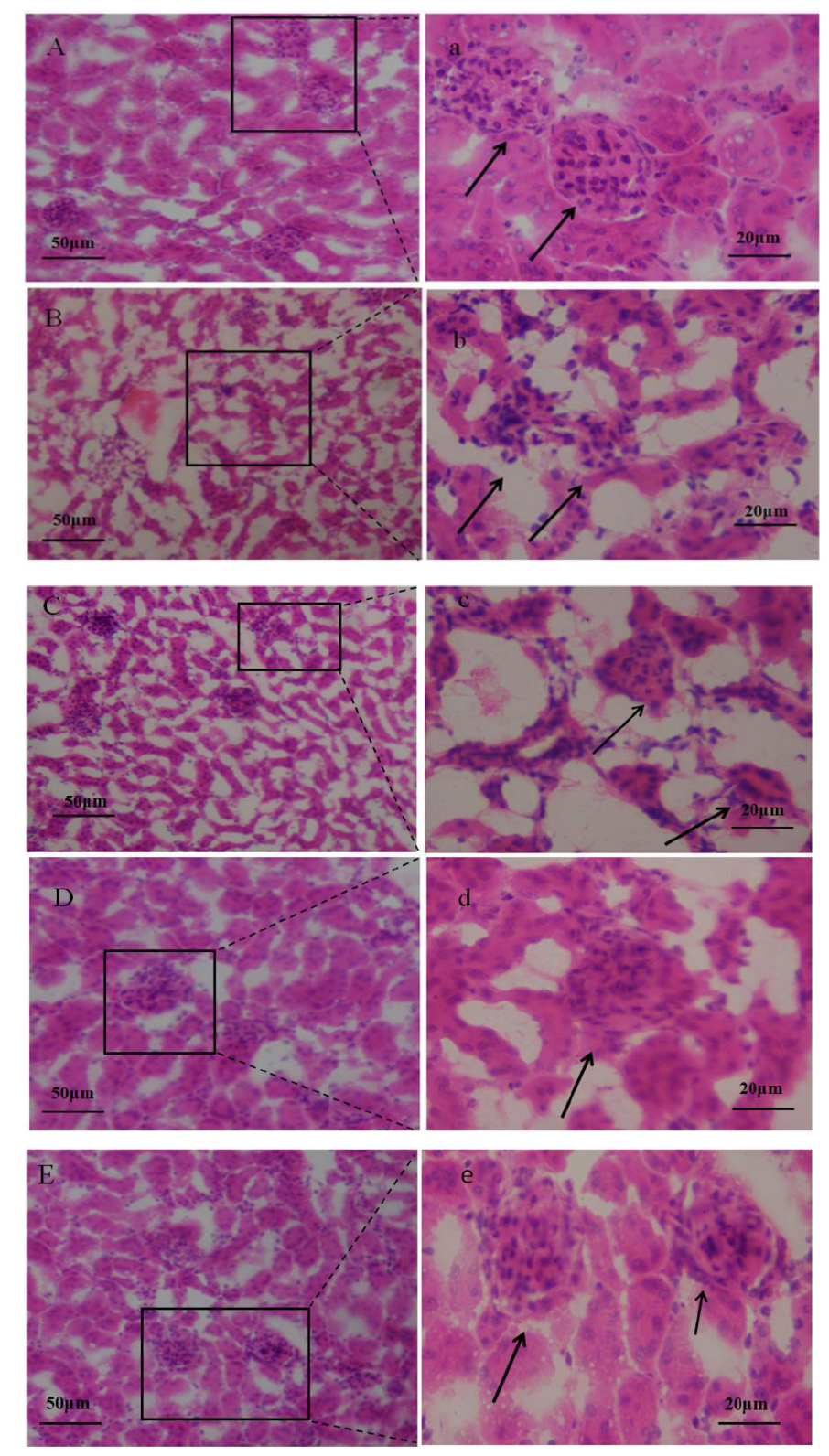

CDDP [4]. In this study, our results demonstrated that SDAPR treatment protected against CDDP-induced nephrotoxicity by limiting oxidative stress, inflammation response, and apoptosis.

Oxidative stress is a vital factor that leads to CDDP nephrotoxicity. Oxidative stress is an imbalance between oxidation and reduction processes, due to the generation of reactive oxygen species [18] that can induce lipid peroxidation production [19]. MDA was measured to assess the level of lipid peroxidation [20]. Previous work showed that CDDP administration results in the overproduction of free radicals. Antioxidant enzymes play critical roles in free radicals elimination [21]. For example, the decreased activity of GSH-px and SOD was significantly restored by morin [22] in CDDP treated mice, resulting in decreased free radical content. CDDP treatment causes a decrease in antioxidant enzyme activity in kidneys, likely from the loss of copper and zinc or by directly binding to sulfhydryl groups on cysteine. In this study, we examined antioxidant enzymes activity (GSH, SOD, and CAT) and lipid peroxidation products (MDA). Our results showed that SDAPR significantly enhanced antioxidant enzymes activity and decreased lipid peroxidation products.

\section{KARGER}


Inflammation plays an important role in CDDP-induced nephrotoxicity in vivo and in vitro. Proinflammatory cytokines showed increased expression at the gene and protein levels after CDDP injection [23]. Among these inflammatory cytokines, TNF- $\alpha$ and IL- 6 are major cytokines that lead to nephrotoxicity [24]. Previous work showed that CDDP administration elicited a 4-fold and 8-fold increase in TNF- $\alpha$ and IL-6, respectively [25]. Inflammatory cells are able to infiltrate renal tissues after CDDP injection [15]. The inhibition of inflammatory cytokines could attenuate renal tissue damage by CDDP [26]. Our results showed that SDAPR markedly reduced the levels of TNF- $\alpha$ and IL- 6 in serum and kidneys.

Apoptosis is a common part of CDDP-induced nephrotoxicity. There is increased inflammation and oxidative stress within renal proximal tubule cells, causing apoptosis and necrosis. Reactive oxygen species play a crucial role in CDDP-induced apoptosis by mitochondrial pathway activation [27]. In addition, the receptor- mediated extrinsic pathway and the endoplasmic reticulum stress pathway are major pathways of apoptosis [28]. Caspase-3 is the most significant effector protease in apoptosis [29]. We evaluated caspase-3, Bax, and Bcl-2 protein expression using western blotting analysis. The results showed that SDAPR significantly ameliorated apoptosis protein expression.

Morphologically, CDDP nephrotoxicity is characterized by the loss of microvilli, tubular cell vacuolization, and tubular dilation [30]. In this study, we found that SDAPR obviously ameliorated CDDP-induced renal structure injury in mice.

In summary, these results suggest that SDAPR can be an effective dietary supplement to relieve CDDP-induced nephrotoxicity in vivo. The protective mechanisms may be attributed to improvement of antioxidant activity, inhibition of inflammation, and the suppression of renal tubular apoptosis by regulating caspase-3 expression.

\section{Acknowledgements}

This work was supported by the Jilin Science and Technology Development Program of China. (Grant no. 20160204004YY)

\section{Disclosure Statement}

The authors declare that there are no conflicts of interest.

\section{References}

-1 McGuire S: World Cancer Report 2014; in Geneva, Switzerland: World Health Organization, Intl Agency Res Cancer, WHO Press, 2015;2:418-419.

-2 Burla S, Domalpally B, Begum N: Adverse drug reaction profiles of commonly used platinum compounds in cancer chemotherapy. Inter J Basic Clin Pharmacol 2015;4:284-289.

- 3 Hato SV: Molecular Pathways: The immunogenic effects of platinum-based chemotherapeutics. Clin Cancer Res 2014;20:2831-2837.

4 Miller RP, Tadagavadi RK, Ramesh G, Reeves WB: Mechanisms of cisplatin nephrotoxicity. Toxins 2010;2:2490-2518.

5 Ciarimboli G: Membrane transporters as mediators of cisplatin side-effects. Anticancer Res 2014;34:547550.

6 Taguchi T, Nazneen A, Abid MR, Razzaque MS: Cisplatin-associated nephrotoxicity and pathological events. Contrib Nephrol 2005;148:107-121.

7 Han X, Yue J, Chesney RW: Functional TauT protects against acute kidney injury. J Am Soc Nephrol 2009;20:1323-1332.

-8 Ma X, Dang C, Kang H, Dai Z, Lin S, Guan H, Liu X, Wang X, Hui W: Saikosaponin-D reduces cisplatin-induced nephrotoxicity by repressing ROS-mediated activation of MAPK and NF- $\mathrm{BB}$ signalling pathways. Int Immunopharmacol 2015;28:399-408. 


\section{Cellular Physiology Cell Physiol Biochem 2017;43:395-404 \begin{tabular}{ll|l} 
and Biochemistry Published onlIne: September 01, 2017 & $\begin{array}{l}\text { (c) } 2017 \text { The Author(s). Published by S. Karger AG, Basel } \\
\text { www.karger.com/cpb }\end{array}$ \\
\hline
\end{tabular}}

Yang et al.: SDAPR Protect CDDP-Induced Nephrotoxicity

9 Kim TW, Kim YJ, Kim HT, Park SR, Lee MY, Park YD, Lee CH, Jung JY: NQO1 Deficiency Leads Enhanced Autophagy in Cisplatin-Induced Acute Kidney Injury Through the AMPK/TSC2/mTOR Signaling Pathway. Antioxid Redox Signal 2016;24: 125-132.

$>10$ Jin J, Li M, Zhao Z, Sun X, Li J, Wang W, Huang M, Huang Z: Protective effect of Wuzhi tablet (Schisandra sphenanthera extract) against cisplatin-induced nephrotoxicity via Nrf2-mediated defense response. Phytomed Int J Phyt Phytopharmacol 2015;22:528-535.

-11 Hagar H, Medany AE, Salam R, Medany GE, Nayal OA: Betaine supplementation mitigates cisplatin-induced nephrotoxicity by abrogation of oxidative/nitrosative stress and suppression of inflammation and apoptosis in rats. Experimental Toxicol Pathol 2015;67:133-141.

12 Kim JB, Bak SG, Jo HG, Cheong SH: Chemical compositions and antioxidant properties of enzymatic hydrolysates from velvet antler in elk (Cervus elaphus canadensis). Res J Pharm Biomed Chem 2016; 3: 2648-2654..

13 Sui Z, Zhang L, Huo Y, Zhang Y: Bioactive components of velvet antlers and their pharmacological properties. J Pharm Biomed Anal 2014;87:229-240.

14 Dong S, Wang H, Wang Q Zhang J: Protective effect of aqueous extract of velvet antler on cisplatin-induced nephrotoxicity in mice. Chin J Path 2016;32:1466-1470.

15 Babu BP, Harihar GC: Amelioration of cisplatin induced nephrotoxicity by standardized methanolic extract of roots of Boerhaavia diffusa. Nat Prod J 2014;4:217-223.

-16 Souza LF, Pagno CH, Medeiros NDS, Barbosa S, Santos PCPD, Rios A, Achaval M, Jong EVD: The effect of the carotenoid bixin and annatto seeds on hematological markers and nephrotoxicity in rats subjected to chronic treatment with cisplatin. Rev Bras De Farm 2016;26:446-450.

$\checkmark 17$ Mashhadi MA, Arab MR, Azizi F, Shahraki MR: Histological study of toxic effects of cisplatin single dose injection on rat kidney. Gene Cell Tissue 2014;1:1-4.

-18 Davis CA, Nick HS, Agarwal A: Manganese superoxide dismutase attenuates Cisplatin-induced renal injury: importance of superoxide. J Am Soc Nephrol 2001;12:2683-2690.

19 Bouaı N, Maatouk I: Microcystin-LR and nodularin induce intracellular glutathione alteration, reactive oxygen species production and lipid peroxidation in primary cultured rat hepatocytes. Toxicol Lett 2004;148:53-63.

20 Dotan Y, Lichtenberg D, Pinchuk I: Lipid peroxidation cannot be used as a universal criterion of oxidative stress. Prog Lipid Res 2004;43:200-227.

21 Yuan Y, Wang H, Wu Y, Zhang B, Wang N, Mao H, Xing C: P53 Contributes to Cisplatin Induced Renal Oxidative Damage via Regulating P66shc and MnSOD. Cell Physiol Biochem 2015;37:1240-1256.

22 Wei Z, He X, Kou J, Wang J, Chen L, Yao M, Zhou E, Fu Y, Guo C, Yang Z: Renoprotective mechanisms of morin in cisplatin-induced kidney injury. Int Immunopharmacol 2015;28:500-506.

-23 Nojiri T, Hosoda H, Kimura T, Tokudome T, Miura K, Takabatake H, Miyazato M, Okumura M, Kangawa K: Protective effects of ghrelin on cisplatin-induced nephrotoxicity in mice. Peptides 2016;82:85-91.

-24 Zhang J, Zhang Y, Xiao F, Liu Y, Wang J, Gao H, Rong S, Yao Y, Li J, Xu G: The peroxisome proliferatoractivated receptor $\gamma$ agonist pioglitazone prevents NF- $\kappa B$ activation in cisplatin nephrotoxicity through the reduction of p65 acetylation via the AMPK-SIRT1/p300 pathway. Biochem Pharmacol 2016;101:100-111.

-25 Ramesh G, Reeves WB: TNF-alpha mediates chemokine and cytokine expression and renal injury in cisplatin nephrotoxicity. J Clin Invest 2002;110:835-842.

26 Lin K, Zhao H, Chen C, Zhang X, Xu M, Duan H: Sappanone a protects mice against cisplatin-induced kidney injury. Int Immunopharmacol 2016;38:246-251.

-27 Behling EB, Sendão MC, Francescato HD, Antunes LM, Costa RS, Bianchi ML: Comparative study of multiple dosage of quercetin against cisplatin-induced nephrotoxicity and oxidative stress in rat kidneys. Pharmacol Rep 2006;58:526-532.

28 Wang X, Grunzborgmann EA, Parrish AR: Loss of $\alpha(E)$-catenin potentiates cisplatin-induced nephrotoxicity via increasing apoptosis in renal tubular epithelial cells. Toxicol Sci 2014;141:254-262.

29 Galluzzi L, Kepp 0, Kroemer G: Caspase-3 and prostaglandins signal for tumor regrowth in cancer therapy. Oncogene 2012;31:2805-2808.

-30 Farooqui Z, Ahmed F, Rizwan F, Shahid F, Khan AA, Khan F: Protective effect of Nigella sativa oil on cisplatin induced nephrotoxicity and oxidative damage in rat kidney. Biomed Pharmacother 2017;85:7-15. 